\title{
Short Report \\ Reexamination of Coccidioides spp. Reserved in the Research Center for Pathogenic Fungi and Microbial Toxicoses, Chiba University, Based on a Multiple Gene Analysis
}

\author{
Ayako Sano, Makoto Miyaji, Katsuhiko Kamei, \\ Yuzuru Mikami, Kazuko Nishimura \\ Research Center for Pathogenic Fungi and Microbial Toxicoses, Chiba University, \\ 1-8-1 Inohana, Chuo-ku, Chiba 260-8673, Japan
}

〔Received: 4, November 2005. Accepted: 12, December 2005]

\begin{abstract}
The Research Center for Pathogenic Fungi and Microbial Toxicoses, Chiba University is the only organization in Japan to possess a series isolates of Coccidioides spp., which are the most virulent pathogenic fungi and which are treated as biosafety level 3 microorganisms. Recently, the genus Coccidioides has been classified into two species, C. immitis and C. posadasii, based on their endemic areas and genotyping; the former species is endemic to the state of California, and the latter is endemic to other parts of North and South America. We reevaluated 19 isolates of Coccidioides immitis stored in our center using a multiple gene analysis. Five isolates were identified as $C$. immitis and 14 as C. posadasii. Their sequence information in GenBank will help to identify the two genospecies of Coccidioides spp.
\end{abstract}

Key words: Coccidioides immitis, Coccidioides posadasii, multiple gene analysis

\section{Introduction}

Coccidioides spp., the causative agents of coccidioidomycosis are the most virulent among pathogenic fungi. Coccidioidomycosis is treated as an imported fungal infection in Japan because almost all the patients were assumed to have gotten the infection in the United States or Mexico. It causes pneumonia and sometimes fatal systemic infection in healthy subjects, and is considered as a category- 4 infection by the Ministry of Health, Labor, and Welfare of Japan. Clinicians who see patients with category-4 infections are required to report them to a local public health center ${ }^{1)}$.

The habitats of Coccidioides spp. are desert areas in North and South America. In Arizona, an endemic area, more than 2,000 new cases per year are reported and more than 100,000 individuals are infected with the fungus without

\footnotetext{
Address correspondence to: Ayako Sano

Research Center for Pathogenic Fungi and Microbial

Toxicoses, Chiba University
}

1-8-1 Inohana, Chuo-ku, Chiba 260-8673, Japan symptoms ${ }^{2)}$. In Japan, more than 45 cases had been recorded as of November 2005 (http:// www.pf.chiba-u.ac.jp/). Most of the Japanese patients were infected in endemic areas to which they had traveled or resided, except for 1 case caused by contact with crude cotton imported from the United States. We could not determine the place of infection for some patients who had traveled to several endemic areas in The United States and Mexico.

The disease is caused by inhalation of arthroconidia of the fungi. The fungi grow as mycelia in spring and produce arthroconidia. They are easily spread into the air by the wind, by new construction activities, and by excavations. The clinical isolates of Coccidioides spp. on slants or plates are also easily diffused into the air and are apt to cause infections in laboratories. The culturing and identification of the fungi by mycological examination require at least 2 weeks for experts with special training ${ }^{1)}$.

C. immitis has been treated as a single species as the causative agent of coccidioidomycosis. Since 2002, C. immitis has been classified into 
two species, C. immitis and C. posadasii, based on the endemic areas and genotypes; the former species is endemic to the state of California, while the latter is endemic to other parts of North and South America ${ }^{3)}$. In 1997, Koufopanou et al. tried to reclassify the species into two geographic types, a California type and an outside-California type, based on the combination of five gene analogues: chitin synthase, dioxygenase (DO), orotidine decarboxylase, serine proteinase (SP), and chitinase $(\mathrm{CT})^{4)}$. Fisher et al. created the two genospecies taxa based on the multiple gene analysis of microsatellites ${ }^{3)}$. They also suggested a convenient method for the differentiation of Coccidioides spp. by a multiple gene analysis using a combination of three gene sequences: DO, SP, and $\mathrm{CT}^{5)}$. The sequence data obtained from their investigations were not released to GenBank completely, because of patenting and bioterrorism crisis-management programs.

The present study aimed to reevaluate 19 strains formerly identified as C. immitis in our center following the criteria for genospecies proposed by Fisher et al. in 2002, to release their sequence data for public convenience, and to clarify the place of infection for Japanese patients. In addition to the genes used by Fisher et al. ${ }^{3)}$, we analyzed the internal transcribed spacer (ITS) 1-5.8S-ITS 2 and the D1/D2 regions of ribosomal RNA genes that are generally used as phylogenetic markers 6,7 ) as well as a partial sequence of the urease gene (URE), which codes the virulence factor of pathogenic fungi ${ }^{8)}$. The present study also tried to find specific genes to classify Coccidioides spp. from the genes named above.

\section{Materials and Methods}

Coccidioides spp. strains examined are shown in Table 1. They were formerly identified as $C$. immitis by the morphology observed through the test tubes, by the patient's history, or by identifications in the original country.

The fungi were cultured at $37^{\circ} \mathrm{C}$ for 2 weeks on potato dextrose agar (Difco, Franklin Lakes, NJ, USA) slants with a silicon plug. Then, a needle with a syringe containing $85 \%$ ethanol was pierced the plug and ethanol was slowly injected until the plug was immersed. The point of needle insertion into the plug was covered with a mass of cotton soaked with $70 \%$ ethanol. The fungal mass was fixed by a final concentration of approximately $70 \%$ ethanol for 48 hours at room temperature. A loop of fungal mass was spread on a PDA plate and cultured at $37^{\circ} \mathrm{C}$ for 7 days to check its survival. The next step was started after we confirmed that the fungus had no sprouts. The above procedures were done in a special laboratory for level 3 biohazard pathogens.

DNA was extracted with a DEXPAT ${ }^{\circledR}$ Kit (TaKaRa, Ohtsu, Japan) with a modification of the manufacturer's protocol. Approximately 100 $\mu l$ of the fungal mass was transferred to a sterilized microtube $(1.5 \mathrm{ml})$, homogenized with $0.5 \mathrm{~m} l$ of DEXPAT $^{\circledR}$ solution by a plastic pestle. The mixture was incubated at $100^{\circ} \mathrm{C}$ for 10 min and centrifuged at 12,000 rpm $(13,201 \mathrm{~g})$ for another $10 \mathrm{~min}$. The supernatant was used

Table 1. Coccidioides spp. isolates and their accession numbers

\begin{tabular}{|c|c|c|c|c|c|c|c|c|c|}
\hline \multicolumn{2}{|r|}{ Isolate } & \multirow[b]{2}{*}{ Identification } & \multirow[b]{2}{*}{ Origin } & \multirow[b]{2}{*}{ Country } & \multicolumn{5}{|c|}{ Gene (length) } \\
\hline IFM No. & Strain & & & & $\begin{array}{c}\text { Deoxygenase } \\
(636)\end{array}$ & $\begin{array}{c}\text { Serine proteinase } \\
(646)\end{array}$ & $\begin{array}{c}\text { Chitinase } \\
(487)\end{array}$ & $\begin{array}{r}\text { Urease } \\
(536)\end{array}$ & $\begin{array}{r}\text { rRNA } \\
(1251) \\
\end{array}$ \\
\hline 4935 & Nagoya & C. posadasii & Human case & Japan & AB232864 & AB232726 & AB232745 & AB232707 & AB232883 \\
\hline 4945 & Ohashi & C. posadasii & Human case & Japan & AB232865 & $\mathrm{AB} 232727$ & AB232746 & $\mathrm{AB} 232708$ & AB232884 \\
\hline 45809 & Silviera（SAP2） & C. posadasii & Animal passage 11 & USA & AB232866 & AB232728 & AB232747 & AB232709 & AB232885 \\
\hline 45810 & Silveira（SAP3） & C. posadasii & Animal passage 111 & USA & $\mathrm{AB} 232867$ & AB232729 & AB232748 & AB232710 & AB232886 \\
\hline 45811 & Arizona & C. posadasii & Human case & USA & AB232868 & AB232730 & AB232749 & AB232711 & AB232887 \\
\hline 45812 & San Antonio & C. posadasii & Human case & USA & AB232869 & AB232731 & $\mathrm{AB} 232750$ & AB232712 & AB232888 \\
\hline 45813 & New York & C. posadasii & Human case & USA & AB232870 & AB232732 & $\mathrm{AB} 232751$ & AB232713 & AB232889 \\
\hline 45815 & $91-48$ & C. immitis & Human case & USA & AB232871 & AB232733 & AB232752 & AB232714 & AB232890 \\
\hline 45816 & $91-153$ & C. immitis & Human case & USA & AB232872 & AB232734 & AB232753 & AB232715 & AB232891 \\
\hline 45817 & Nicols & C. posadasii & Human case & USA & AB232873 & AB232735 & AB232754 & AB232716 & AB232892 \\
\hline 46868 & Yokohama & C. immitis & Human case & Japan & AB232874 & AB232736 & AB232755 & AB232717 & AB232893 \\
\hline 50992 & $90-242$ & C. immitis & Human case & USA & AB232875 & AB232737 & AB232756 & AB232718 & AB232894 \\
\hline 50993 & Kanazawa & C. posadasii & Human case & Japan & AB232876 & AB232738 & AB232757 & AB232719 & AB232895 \\
\hline 50994 & Toranomon & C. posadasii & Human case & Japan & AB232877 & AB232739 & AB232758 & AB232720 & AB232896 \\
\hline 50995 & Handai & C. immitis & Human case & Japan & AB232878 & AB232740 & AB232759 & AB232721 & AB232897 \\
\hline 51112 & Himeji & C. posadasii & Human case & Japan & AB232879 & AB232741 & $\mathrm{AB} 232760$ & AB232722 & AB232898 \\
\hline 54194 & Nagano & C. posadasii & Human case & Japan & AB232880 & AB232742 & AB232761 & AB232723 & AB232899 \\
\hline 54195 & Fukunaga & C. posadasii & Human case & Japan & AB232881 & AB232743 & AB232762 & AB232724 & AB232900 \\
\hline 54196 & Chiba & C. posadasii & Human case & Japan & AB232882 & AB232744 & AB232763 & AB232725 & AB232901 \\
\hline
\end{tabular}


as the DNA sample ${ }^{9)}$. DNA extract $(2.5 \mu l)$, Ready-to-Go beads (Amersham Pharmacia, Tokyo, Japan), $20 \mu l$ of distilled water, and $2.5 \mu l$ of $10 \mathrm{pM}$ of each primer for DO, SP, CT, and rRNA genes ${ }^{4-7)}$ were mixed, and polymerase chain reactions (PCR) were processed. PCR products were separated by electrophoresis on $1.0 \%$ agarose gels in $1 \times$ TBE buffer $(0.04 \mathrm{M}$ Trisboric acid, $0.001 \mathrm{M}$ EDTA $\mathrm{pH}$ 8.0) and visualized by ethidium bromide staining. PCR products were purified with a PCR purification kit (QIAquick ${ }^{\circledR}$, Qiagen) and labeled using BigDye ${ }^{\circledR}$ terminator Ver. 1.1 (Applied Biosystems, Foster City, CA, USA) by the manufacturer's protocol.

The partial sequence of the urease gene (URE) was amplified with a primer set (CIS2410-2434: CGG GTA TTT ACA AGG CTG ATA TTG G and CIAS2945-2922: GAA GCC AGA TTC GTT CAG GGT GTC) designed from the $C$. immitis urease gene sequence deposited in GenBank under accession number U815098). The PCR conditions for URE were as follows: the reaction mixture was subjected to 1 cycle of denaturation at $95^{\circ} \mathrm{C}$ for $4 \mathrm{~min}$, 30 cycles of amplification at $94^{\circ} \mathrm{C}$ for $1 \mathrm{~min}$, at $50^{\circ} \mathrm{C}$ for $1 \mathrm{~min}$, and at $72^{\circ} \mathrm{C}$ for $2 \mathrm{~min}$, and a final extension cycle at $72^{\circ} \mathrm{C}$ for $10 \mathrm{~min}$ with a PCR Thermal Cycler MP (TaKaRa).

The combined data set for phylogenic study was performed in Fusarium spp. ${ }^{10)}$. The present study applied above analysis for alignment of combined sequences consisted of at least 1,769 base pairs obtained from the DO, SP, and CT genes using CLUSTAL X (Version 1.8) ${ }^{11)}$. An unrooted tree was constructed using Njplot (http://pbil.univ-lyon1.fr/software/njplot.html) ${ }^{12}$. The trees were also constructed based on each gene alone. Consistencies in clade formation between the unrooted trees based on each gene and the combined one were compared.

The genospecies of Coccidioides were determined based on the location of the clade. Strains located in the clade involving IFM 50995 derived from a Japanese patient whose infection was suspected of having occurred in Bakersfield, California ${ }^{13)}$ was identified as Coccidioides immitis, and those in the clade with IFM 45811 and IFM 45812 originating in the state of Arizona were identified as Coccidioides posadasii, respectively.

\section{Results and Discussion}

The accession numbers of the genes, the lengths of the sequences, and the identification based on the cluster analysis with the threegene combination are shown in Table 1 . The unrooted tree based on a combination of three genes is shown in Fig. 1. Five isolates of Coccidioides spp. in our center were identified as

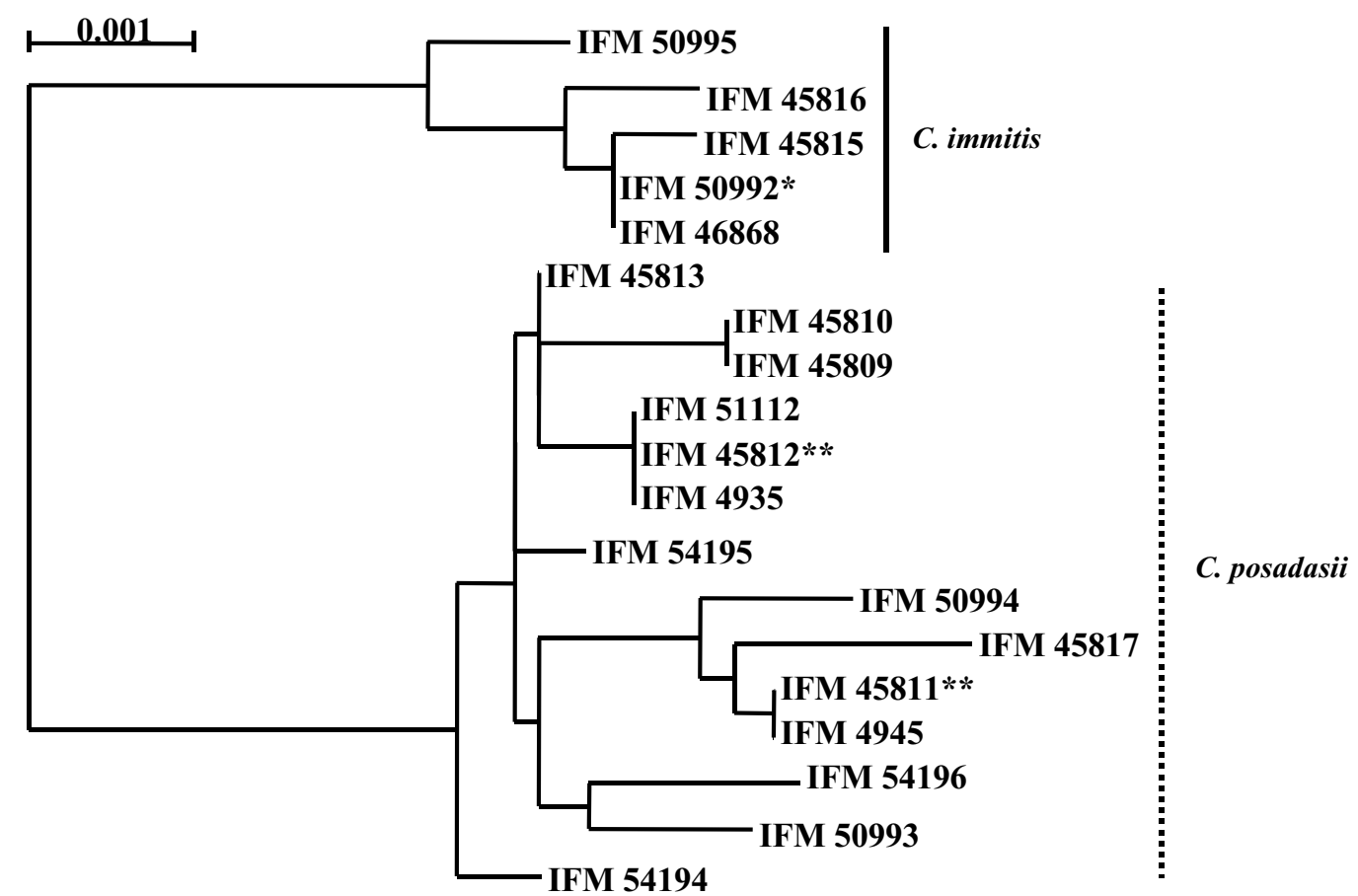

Fig. 1. Unrooted tree based on a combination of three gene sequences-dioxygenase (DO), serine proteinase (SP), and chitinase (CT) consisting of 1769 base pairs constructed by the neighbor-joining method. The scale bar represents a difference corresponding to $0.001(0.1 \%)$. Isolates identified as $C$. immitis are in the upper clade and those as $C$. posadasii are in the lower one. *: isolate used as C. immitis standard; **: isolate used as C. posadasii standard. 
C. immitis and 14 as $C$. posadasii. The data confirmed that 2 of the Japanese cases were caused by $C$. immitis.

Unrooted trees based on individual DO, SP, and URE genes were consistent with the combination of three genes (DO, SP, and CT) and could separate two clades, while those of CT and rRNA genes could not (data not shown). The homology among isolates was more than $99 \%$ in all genes evaluated.

The GenBank database was not sufficient for genetic identification of Coccidioides spp. There was one sequence of $\mathrm{DO}$ on $C$. posadasii (L38493), four sequences of SP on C. immitis (S77562, AJ408857, AJ408861, and M81863) and four sequences on C. posadasii (AJ408858, AJ408859, AJ408860, and X63114), three sequences of CT on C. posadasii (L41663, U51271, and U60806), one sequence of URE on C. posadasii (U81509), two sequences of the ITS region of rRNA on C. posadasii (CIU18360, X94142), and two sequences of the $\mathrm{D} 1 / \mathrm{D} 2$ region of $\mathrm{rRNA}$ on C. immitis (AY176713, AB040702). The gene sequences of the species used for the present study are helpful for genetic identification. Cluster analysis in the present study with a combination of these data found an inconsistency on the SP gene. The sequence AJ408857, derived from $C$. immitis in the GenBank database, was located on the cluster of $C$. posadasii.

Thus far, two genes, DO and URE, might be useful for identifying genospecies of Coccidioides spp. alone. Such an analysis will allow speculation on where infection occured, while both the ITS and D1/D2 regions of rRNA genes, which are representative genetic markers for classifying and identifying fungal species ${ }^{6,}$ 7), were incompatible with the unrooted tree based on the cluster analysis by combination of the three genes. Identification based on ribosomal RNA genes could not identify the species of Coccidioides because of strongly similar identity among strains according to the criteria proposed by Kurtzman and Robnett ${ }^{7)}$.

The inter species differences between $C$. immitis and $C$. posadasii linked both geographic distribution and virulence ${ }^{5)}$. However, clinical isolates of both C. immitis and C. posadasii in Japan should be regarded as the most virulent fungal species. We should keep in mind that the clinical isolates of Coccidioides spp. should be handled in accordance with biohazard regulations at a bio-safety level 3 laboratory.

\section{Acknowledgements}

The present study was supported by the National Bioresource Project supported by the Ministry of Education, Culture, Sports, Science, and Technology, Japan, and by the Special Research Fund for Emerging and Re-emerging Infections by the Ministry of Health, Labor, and Welfare, Japan.

\section{References}

1) Kamei K: Imported mycoses in Japan: Their present status and problems. Jpn J Med Mycol 46: 17-20, 2005.

2) Cox RA, Magee DM: Coccidioidomycosis: host response and vaccine development. Clin Microbiol Rev 17: 804-839, 2004.

3) Fisher MC, Koenig GL, White TJ, Taylor JW: Molecular and phenotypic description of Coccidioides posadasii sp. nov., previously recognized as the non-California population of Coccidioides immitis. Mycologia 94: 73-84, 2002.

4) Koufopanou V, Burt A, Taylor JW: Concordance of gene genealogies reveals reproductive isolation in the pathogenic fungus Coccidioides immitis. Proc Natl Acad Sci USA 94: 54785482, 1997.

5) Fisher MC, Koenig GL, White TJ, San-Blas G, Negroni R, Alvarez IG, Wanke B, Taylor JW: Biogeographic range expansion into South America by Coccidioides immitis mirrors new world patterns of human migration. Proc Natl Acad Sci USA 98: 4558-4562, 2001.

6) White TJ, Bruns T, Lee S, Taylor J: Amplification and direct sequencing of fungal ribosomal RNA genes for phylogenetics. In: M.A. Innis, D.H. Gelfard, J.J. Sniinski, and T.J. White, Editors, PCR protocols: A guide to methods and applications, Academic Press Inc., San Diego, CA, pp.315-322, 1990.

7) Kurtzman CP, Robnett CJ: Identification of clinically important ascomycetous yeasts based on nucleotide divergence in the $5^{\prime}$ end of the large-subunit (26S) ribosomal DNA gene. J Clin Microb 35: 1216-1223, 1997.

8) Yu JJ, Smithson SL, Thomas PW, Kirkland TN, Cole GT: Isolation and characterization of the urease gene (URE) from the pathogenic fungus Coccidioides immitis. Gene 198: 387-391, 1997

9) Endo S, Komori T, Ricci G, Sano A, Yokoyama K, Ohori A, Kamei K, Franco M, Miyaji M, Nishimura K: Detection of gp43 of Paracoccidioides brasiliensis by the loop-mediated isothermal amplification (LAMP) method. FEMS Microbiol Lett. 234: 93-97, 2004.

10) Aoki T, O'Donnell K, Scandiani MM: Sudden death syndrome of soybean in South America is caused by four species of Fusarium: Fusarium brasiliense sp. nov., F. cuneirostrum sp. nov., F. 
tucumaniae, and F. virguliforme. Mycosciense 46: 162-183, 2005.

11) Jeanmougin F, Thompson JD: Multiple sequence alignment with Clustal X. Trends Biochem Sci 23: 403-405, 1998.

12) Perrière G, Gouy M: WWW-Query: an on-line retrieval system for biological sequence banks.
Biochimie 78: 364-369, 1996.

13) Osaki $T$, Morishita H, Maeda H, Kamei K, Hoshino S, Kijima T, Kumagai T, Yoshida M, Tachibana I, Kawase I: Pulmonary coccidioidomycosis that formed a fungus ball with 8-years duration. Internal Medicine 44: 141-144, 2005. 